\title{
Reduction of Railway-induced Vibration using In-filled Trenches with Pipes
}

\begin{abstract}
Araz Hasheminezhad $^{\dagger}$
Abstract

Reduction in railway-induced vibrations in urban areas is a very challenging task in railway transportation. Many mitigation measures can be considered and applied. Among these, a little attention has been paid to trenches. In this study, a numerical investigation on the effectiveness of in-filled trenches with pipes in reducing railway vibrations due to passing trains is presented. Particularly, a series of two-dimensional dynamic analysis was performed to model the behavior of ballasted railway track under harmonic load with ABAQUS software as a Finite Element method. In so doing, two types of in-filled trenches with pipes with steel and concrete materials have been investigated in this paper. In addition, effectiveness of pipes made of steel and concrete, filled with loose sand and clay in railway-induced vibration reduction has been assessed. The results point out that using in-filled trench with pipes does not effective a lot on railway-induced vibration reduction in comparison to other railway-induced vibration reduction methods. However, in-filled trenches with steel pipes are much more effective than in-filled trenches with concrete pipes. Moreover, filling pipes with loose sand and clay does not have any effect on vibration reduction efficiency of these in-filled trenches.
\end{abstract}

Keywords: Vibration reduction, In-filled trenches, Finite element method, Pipe

\section{Introduction}

Vibration induced by railways is a major environmental concern in urban areas. These vibrations propagate through the surrounding soil into nearby buildings, causing annoyance to people. Vibrations due to railway traffic are generated by dynamic interaction between the wheels and the rails due to wheel and rail unevenness. Vehicletrack interaction results in dynamic axle loads, which are transferred by the track to the soil. Vibrations propagate as elastic waves in the soil and excite nearby buildings through the foundations. Up to now, many researches has been performed to obtain efficient and cost-effective vibration mitigation measures. In recent years, the requirement of considering the environmental influence in planning and designing traffic systems becomes stronger and stron-

\footnotetext{
Corresponding author: School of Railway Engineering, Iran University of Science and Technology, Iran

E-mail : Araz hasheminezhad@rail.iust.ac.ir

(c) The Korean Society for Railway 2014

http://dx.doi.org/10.7782/IJR.2014.7.1.016
}

ger. In the past, the cities were small and the buildings were relatively sparse, thus traffic-induced vibration was not considered as an environmental problem. While at present, with the rapid growth of modern cities, the metro lines, urban railways and elevated traffic roads are increasingly forming a multi-dimensional traffic system, extending and intruding from underground, ground and overhead into the crowded residence areas, and even cultural and research zones. At the same time, the traffic flows are getting more and more intense, traffic loads becoming heavier and heavier, and traffic vehicles running faster and faster. All of these make the influences of traffic-induced vibrations more and more serious. Vibrations induced by railway vehicles running underneath or close to buildings may become considerable. They propagate underground or along the ground surface, and furthermore induce the secondary vibrations of the buildings, which seriously affect the structural safety of the ancient buildings and the daily life of the people inside the buildings near the railway traffic lines. In Iran, some ancient buildings of masonry structures beside the subway were cracked owing to the vibrations induced by the passing vehicles (Fig. 1). With 
the enlargement of the cracks, some old churches and houses were damaged. According to an investigation in Japan by XIA He and his colleagues in 2007, one of the highest complaint rates on traffic-induced vibrations is their influence on the damage of buildings, which is about $20 \%$ of the total complaints, as shown in Fig. 2. In this study, phenomenon of railway-induced vibration has been modeled with the numerical finite/infinite element method and then efficiency of in-filled trenches with pipes in railway vibration reduction has been assessed. In addition, a
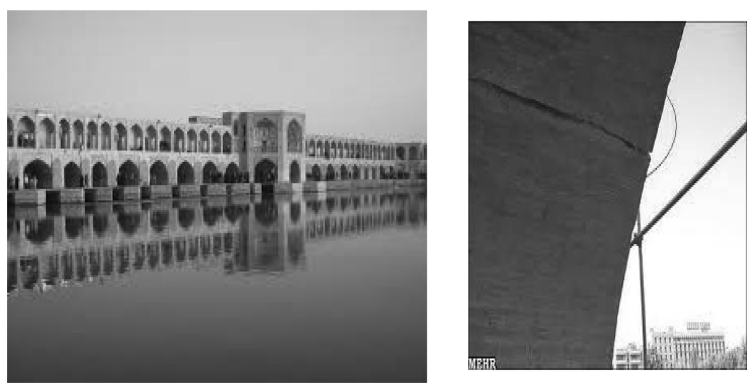

Fig. 1 Crack of a historical bridge due to Subway vibration in Iran

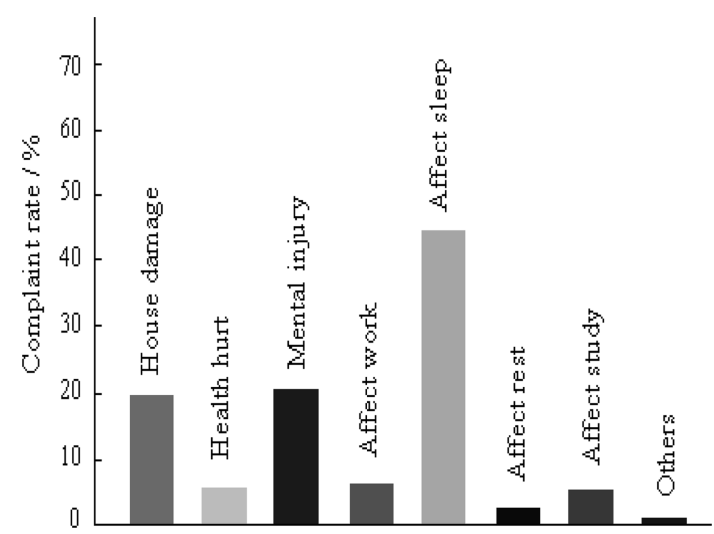

Fig. 2 Public complaints on traffic-induced vibration comprehensive review has been made into railwayinduced vibration reduction methods in particular trenches as follows.

\section{Railway-Induced Vibration Reduction Methods}

Purpose of reducing vibration is minimizing the undesirable effects of vibration, which can have on humans and the environment. There are several methods for reducing vibration: such as source isolation, the impairment of vibration isolation and receivers like buildings. To select vibration reduction technology depends on several factors and not just consider the cost and feasibility of implementation. Therefore, improving the accuracy of prediction of vibration is of great importance in the development of vibration control guidelines. In other words, the vibration reduction methods can be divided into three groups including: vibration reduction methods in source, vibration reduction methods in propagation path and vibration reduction methods in receiver, which are indicated in Fig. 3. Most of the existing floating slabs have been designed to control ground borne noise; however, by reducing the fundamental natural frequency of the floating slab system, they can be equally effective at controlling perceptible ground borne vibration (Fig. 4). There are also several other measures to reduce vibration as rail grinding, resilient fastening systems, ballast mats, which are less complex and costly with also some limitations. In order to reduce amplitudes of vibrations on the track, grinding of rails has been used for several years on railway networks. This method is usually used in tracks, which has rail with distortion. Reductions of $40-90 \%$ for normally worn rails, or $90-98 \%$ for corrugated rails, can be achieved. Resilient direct fixation fasteners are used in surface or underground railways. They are used to reduce vibrations and

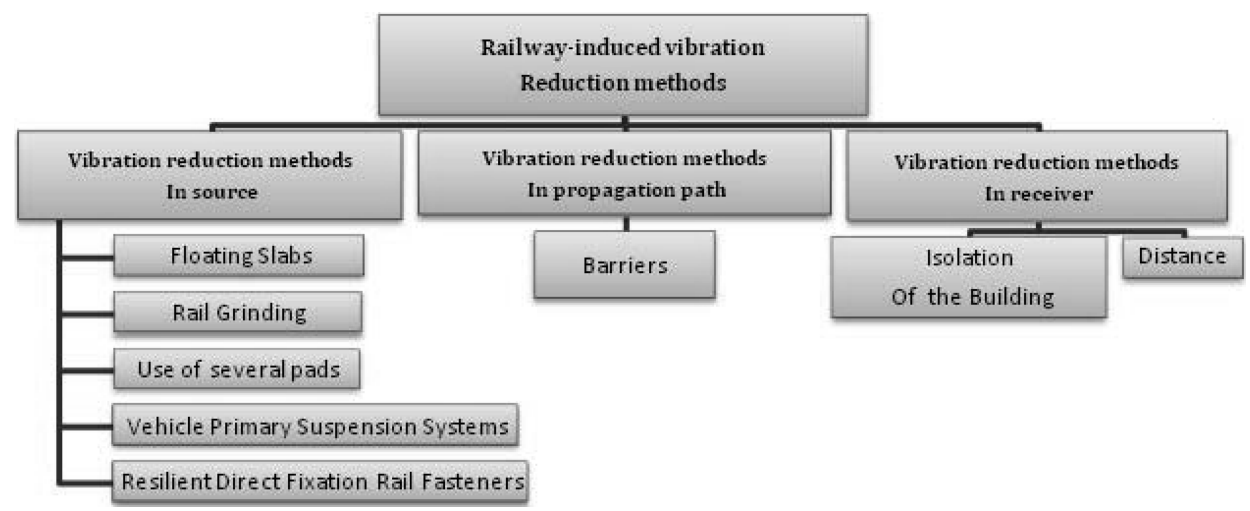

Fig. 3 Reduction methods of railway-induced vibration 


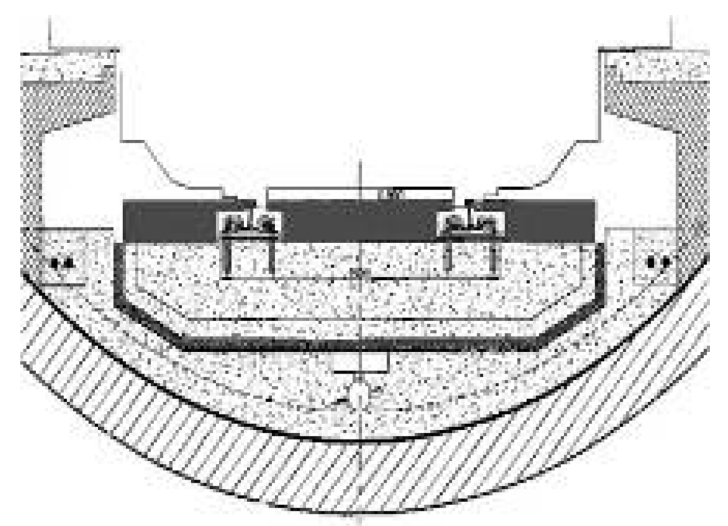

Fig. 4 Reduction in source

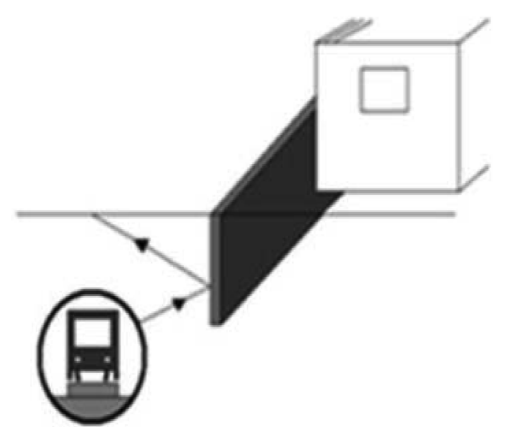

Fig. 5 Reduction in path

noise at frequencies above $30 \mathrm{~Hz}$. Design of vehicle primary suspension system is not part of the track design, but has a direct effect on the amplitude of ground borne vibration along the track. To select vibration isolation depends on the type of vehicle used. In general, vehicles with low stiffness primary suspension systems can cause lower vibration levels in comparison with high stiffness primary suspension systems. Using low stiffness primary suspension systems can reduce vibrations in the frequency range $10-31.5 \mathrm{~Hz}$, so that there is no need to use other types of vibration isolations. Elastic elements in a wide variety of tracks are used to increase the elastic properties. The pads play an important role in enhancing the elasticity. Solutions to reduce noise and vibration and increasing the elasticity of non-conventional tracks are the usage of elastic supports under the concrete slab, using elastic fastenings on non-conventional tracks and pads under the base plate. Ballast mats can provide attenuation as high as 10 to 15 $\mathrm{dB}$ at frequencies above 25 to $30 \mathrm{~Hz}$. Ballast mats is the most convenient vibration reduction method for current tracks with high vibration problem.

If only one or a few buildings are affected by the excessive ground-borne vibration from the railway, alternative

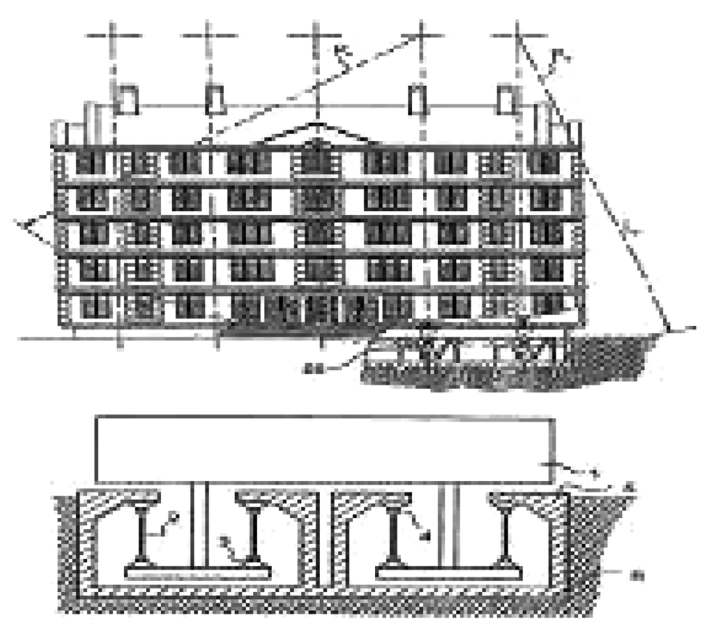

Fig. 6 Reduction in receiver

methods such as building isolation may prove to be suitable. There are a number of methods that can be employed to reduce the vibration levels in buildings. Some of these methods can be used to mitigate vibration problems that arise post-construction. Damping treatments (such as freelayer damping and constrained layer damping) can be applied to resonant floors or walls, and tuned vibration absorbers can be installed to attenuate specific resonant frequencies. Localized stiffening or mass addition can be used to move structural resonances away from the excitation frequency. Furniture designs can be selected so that they do not resonate at the excitation frequencies, and sensitive equipment can be moved near to the walls, where the vibration levels are likely to be lower than at the center of the floor. Buildings by elastic foundation isolation system are shown schematically in Fig. 6.

\section{Literature survey on using Trenches as a Railway-induced Vibration Reduction Method}

Some common vibration countermeasures that involve disruption of the transmission path include the construction of barriers (Fig. 5) including open trenches, in-filled trenches; wave-impeding blocks (WIBs) and pile rows. Use of trenches for control of ground borne vibrations is similar to control of noise through the sound barrier. These methods have been investigated in experimental and numerical studies. A study on the effectiveness of open trenches, in-filled trenches and a WIB in reducing ground borne vibration is conducted by Hung et al. (2004) using a 2.5D finite/infinite-element approach. Their findings show that open trenches are the most effective method of isolat- 


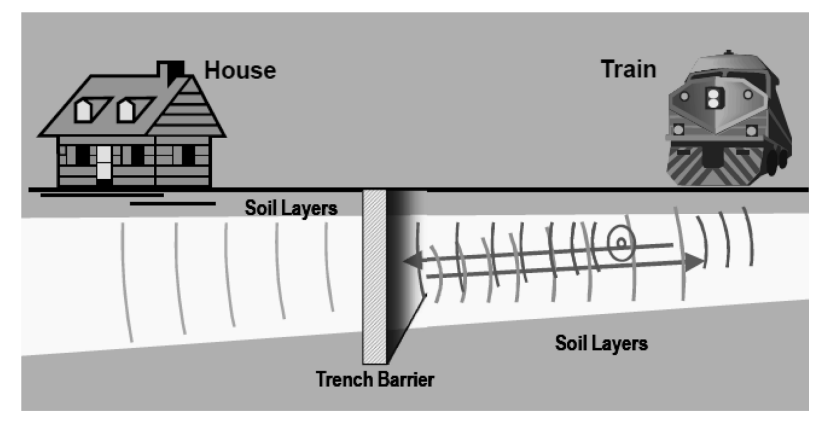

Fig. 7 Trench Barrier performance in Railway-induced vibrations

ing the vibrations induced by the static and dynamic moving loads produced by trains. The WIB is seen to be effective only in isolating vibrations with wavelengths comparable to the dimensions of the WIB itself. Yang and Hung (1997) determined the optimal parameter values for these three barriers in isolating the train induced vibrations. In another study, Woods (1968) investigated the efficiency of open trenches in the attenuation of vibrations by means of laboratory tests. Lysmer and Waas (1972) used a lumped mass system to study effect of trench on reducing the induced shear waves of rigid foundation under harmonic load. Segol et al. (1978) used a finite element model with absorbing boundaries to study effect of open and in-filled betonies - slurry trenches on vibration reduction in layered soil.

During the last decades, a great part of the studies on wave propagation problems was performed by the boundary element method (BEM). This method is very well suited for wave propagation problems in soils because the radiation condition at the boundary is automatically accounted. Many authors adopted the BEM for the analysis of isolation effects of open and in-filled trenches in different types of soils and to present a simplified design method using empirical formulae. However, the boundary element method is not suitable for modeling of irregularities in geometry or material of the foundation and soils. Efforts have been directed mainly towards the analytical studies and experimental works to investigate the problems of isolation by trench barriers. The few experimental studies presented some design guidelines for particular cases but they were rather limited in their scope. Woods and Haupt (1968) conducted a series of field tests, analytical studies and laboratory model experiments to study the screening performance of open trenches and concrete walls. In addition, the wave diffraction by spherical and parabolic obstacles has been studied analytically. However, the closed form solutions were confined to simple geometries and idealized conditions. Starting from mid 1970 s, various numerical methods emerged as an effective tool for solving wave propagation and vibration reduction problems. Lysmer and Wass (1972) employed the lumped mass method while others applied the finite elements along with special non-reflecting boundaries to investigate the isolation efficiency of open and betoniesslurry-filled trenches in layered soil. The finite difference technique was also used to study scattering of a Rayleigh wavelet by a rectangular open trench. Nevertheless, due to the constraints of the used numerical algorithms, underlying bedrock has to be inevitably included in the analysis models along with some sort of artificial transmitting boundaries. Trenches including open and in-filled trenches have been used for reduction of railway-induced vibrations. Researchers who investigate in this field follow Segol et al. (1978) used finite element along with a special energy absorber for the effect of open and in-filled (betonies-slurry) trenches in layered soil. In another study, woods (1968) investigated experimental study for the effectiveness of open trenches in the reduction of vibrations. In addition, Thau and Pao (1966) used analytical methods for studying the fractured waves around obstacles in the spherical and parabolic forms. Yang and Hung (2008) and Hung et al. (2004) have used two-dimensional finite/infinite and semi three-dimensional elements for analysis of the open trenches, in-filled trenches and elastic foundation parametrically. Other researches in this area in recent years have been carried out by Andersen and Nielsen (2005), Karlström and Boström (2007), Guang Yun et al. (2008), Yang and Hung (2008), Müller (2008), Di Mino et al. (2009), Kawamura et al. (2010) and Sivakumar Babu et al. (2011). In a recent study, Zakeri et al. (2013) investigated the effectiveness of step shaped trench on reduction of railway-induced vibrations on a neighbor structures. During the last decades, although there have been considerable developments in control and mitigation of railway-induced vibration, but it is evident that further research is required especially in using in-filled trenches with pipes.

\section{Numerical Model Specifications}

The propagation of vibrations is a typical three-dimensional issue, especially in railway field where the train acts as a series of incoherent point source rather than a fully coherent line source. So three-dimensional models are certainly more suitable to predict the absolute vibration but require computation times not always consistent with extensive analyses. In the light of this, the 2D model has been considered appropriate to output results consistent 


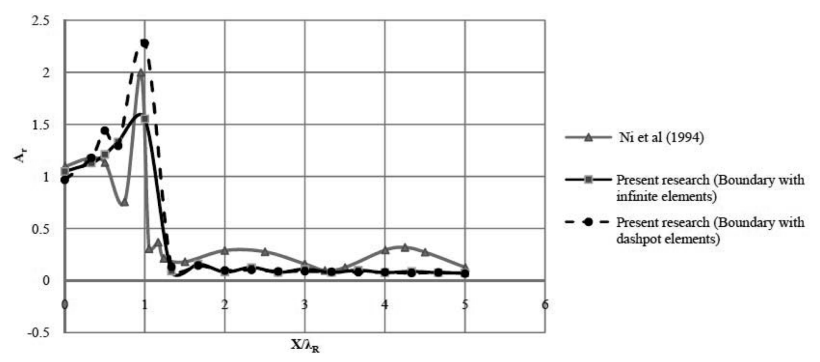

Fig. 8 The effect of open trenches with harmonic load (Zakeri et al ,2013)

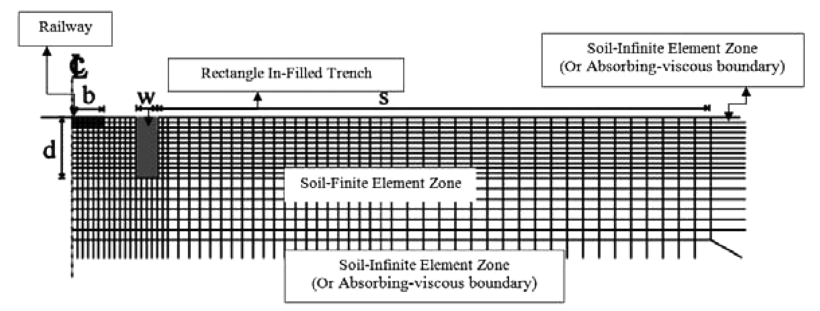

Fig. 9 Mesh Network with Finite/Infinite element with trench

with the aim of the present study. In this part, a numerical analysis has been carried out using ABAQUS software for defined elements, on a two-dimensional modeling of the studied system. The geometrical parameters of the in-filled trench for numerical analyses are adopted: depth of trench $\mathrm{d}=\mathrm{D} \cdot \lambda_{\mathrm{R}}$, width of trench $\mathrm{w}=\mathrm{W} \cdot \lambda_{\mathrm{R}}$, distance from the centerline of the railway $\mathrm{l}=\mathrm{L} \cdot \lambda_{\mathrm{R}}$, half width of railway $\mathrm{b}=\mathrm{B} . \lambda_{\mathrm{R}}$, and range of measurement $\mathrm{s}=\mathrm{S} . \lambda_{\mathrm{R}}$, where $\mathrm{L}, \mathrm{D}$ and $\mathrm{W}$ are non-dimensional parameters and $\lambda_{\mathrm{R}}$ is the Rayleigh wavelength. These parameters are all normalized to make the results independent of the excitation frequencies. With respect to considered data for the in-filled trenches including distance from the centerline of the railway $\mathrm{L}=1$, width $\mathrm{W}=1 / 3$, depth $\mathrm{D}=1$ and range of measurement $S=9$. In addition, the material properties have been listed in Table 1. For considering open trenches near railway tracks, two parallel empty trenches can be constructed alongside the railway tracks, in a manner symmetric to the centerline of the railway, as only half of the problem needs to be considered for analysis. The geometry of problem has a near field and a semi-infinite far field as shown in Fig. 9. The near field consists of the wave barrier (trench), railway and surrounding soils, which are irregular in terms of material and geometry. Conditions of Plane strain are supposed for the twodimensional profile of the half-space. The traffic load applying at the centerline of the railway can always be expressed as a series of harmonic loads. Besides, hysteretic damping is supposed for the soil, which is modeled as
Table 1 Soil, In-filled trench and railway properties

\begin{tabular}{ccccc}
\hline \hline Material & $\begin{array}{c}\text { Young's } \\
\text { Modulus } \\
\text { E (MPa) }\end{array}$ & $\begin{array}{c}\text { Poisson's } \\
\text { Ratio }(v)\end{array}$ & $\begin{array}{c}\text { Density } \\
\rho(\mathrm{kg} / \mathrm{m})\end{array}$ & $\begin{array}{c}\text { Damping } \\
\text { Ratio }(\beta)\end{array}$ \\
\hline Soil & 46 & 0.25 & 1800 & 0.05 \\
\hline $\begin{array}{c}\text { In-Filled } \\
\text { Trench }\end{array}$ & 4600 & 0.25 & 2700 & 0.05 \\
\hline $\begin{array}{c}\text { Railway } \\
\text { Foundation }\end{array}$ & 13500 & 0.25 & 2400 & 0.02 \\
\hline
\end{tabular}

Table 2 pipes material and pipes inside material properties

\begin{tabular}{cccc}
\hline \hline Material & $\begin{array}{c}\text { Density } \\
\rho(\mathrm{kg} / \mathrm{m})\end{array}$ & $\begin{array}{c}\text { Young's Modulus } \\
\mathrm{E}(\mathrm{MPa})\end{array}$ & $\begin{array}{c}\text { Poisson's } \\
\text { Ratio }(v)\end{array}$ \\
\hline Loose sand & 1800 & 18500 & 0.3 \\
\hline Clay & 1520 & 10000 & 0.5 \\
\hline Steel Pipes & 7950 & & 0.2 \\
\hline $\begin{array}{c}\text { Reinforced } \\
\text { Concrete Pipes }\end{array}$ & 2500 & & 0.175 \\
\hline
\end{tabular}

an isotropic visco-elastic medium. Since most of the previous works have dealt with harmonic load of certain single frequency, it was common to relate each parameter to the Rayleigh wavelength $\mathrm{L}_{\mathrm{r}}$ that depends on the applied frequency and the soil properties. In so doing, in this paper first the model has been verified with Ni et al (1994) and then the effect of harmonic load due to train has been investigated. As shown in Fig. 8, results of the numerical solution were compared with the numerical results of $\mathrm{Ni}$ et al. (1994). In this Figure, $A_{\mathrm{r}}$ (The index of amplitude reduction ratio) has been utilized for investigating efficiency and performance of trenches in order to reduce railway-induced vibration with the following definition in terms of ground surface displacement (Beskos et al., 1986, Ni et al., 1994, Ahmad et al., 1996, Yang and Hung, 2008)). Values were plotted versus normalized horizontal distance of receiver points. Two groups of the numerical results in this figure were implied selecting two different approaches for boundary conditions; i.e. infinite or dashpot elements in the model. Good agreement of the obtained numerical results with those reported by $\mathrm{Ni}$ et al. (1994) confirmed reliability of the developed model in ABAQUS. Soil properties include shear wave velocity, $\mathrm{C}_{\mathrm{S}}$ $=(\mathrm{G} / \rho){ }^{\wedge} 1 / 2=(18.4 \times 106 / 1800) \wedge 1 / 2=101.11 \mathrm{~m} / \mathrm{s}$, wave Rayleigh velocity $\mathrm{C}_{\mathrm{R}}=\mathrm{C}_{\mathrm{S}}(0.87+1.12 \mathrm{~V}) /(1+\mathrm{V})$ $=93.02 \mathrm{~m} / \mathrm{s}$ and Rayleigh wavelength $\lambda_{R}=C_{R} / f=93.02 /$ $31=3 \mathrm{~m}$ (Yang and Hung, 2008). In this regard, both boundary conditions (Finite/Infinite Elements or boundary energy absorber) have been investigated and compared.

In this paper, the screening performance of two types of 


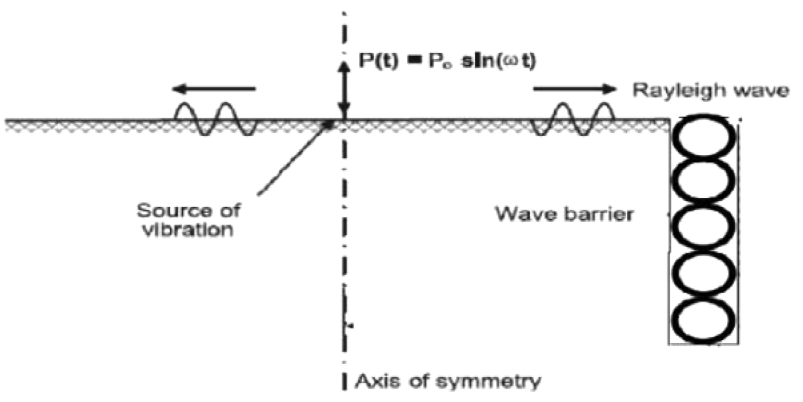

Fig. 10. Modeling scheme and loading pattern

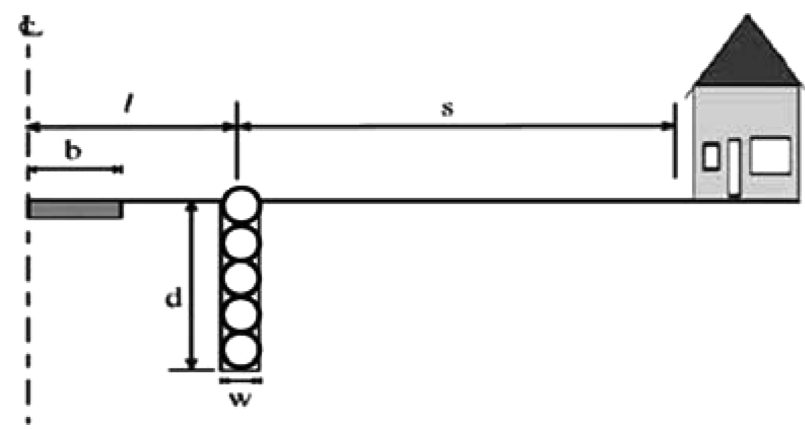

Fig.11. Schematic detail of In-filled trench with empty pipes problem definition

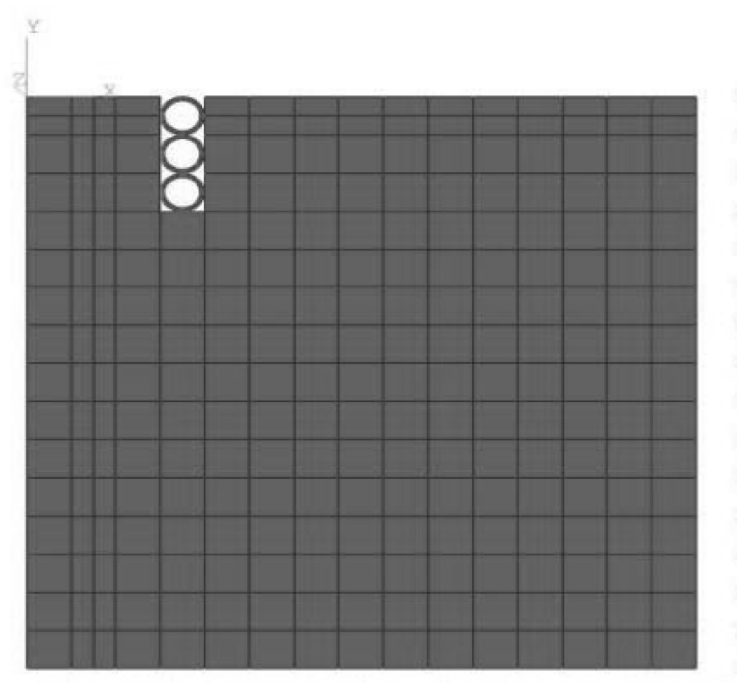

Fig.12. ABAQUS Model of In-filled trench with empty pipes problem

in-filled trenches with pipes including steel pipes and concrete pipes, excavated in a soil layer over bedrock, has been studied and compared. Also in progress, each of previous mentioned in-filled trenches, this time will be filled with loose sand and clay in ABAQUS modeling and their effects on railway-induced vibration will be discussed. By

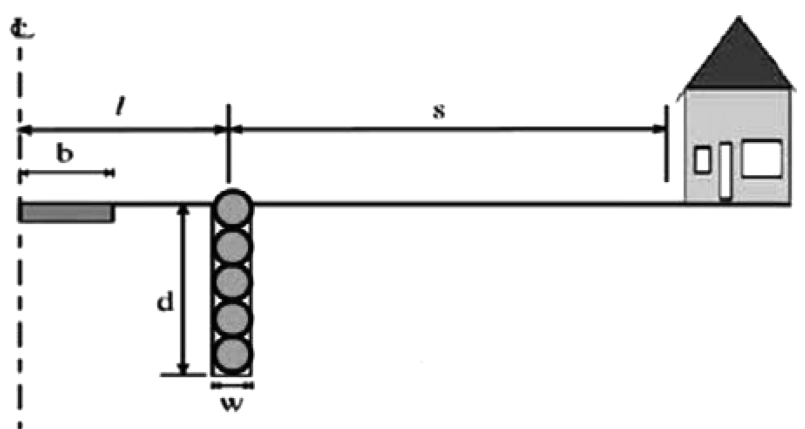

Fig.13. Schematic detail of In-filled trench with full pipes problem definition

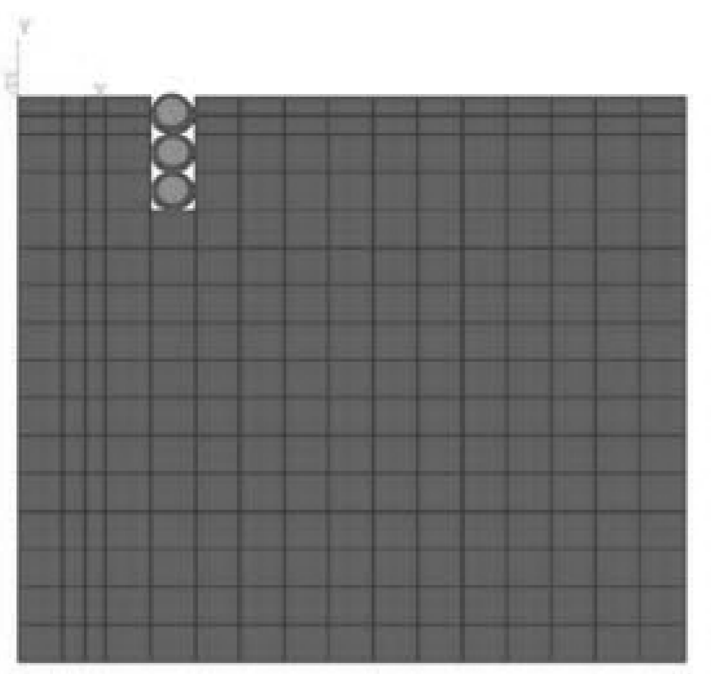

Fig.14. ABAQUS Model of In-filled trench with full pipes problem

applying a 2D FEM model, an extensive analysis has been carried out to the aim of determining the effectiveness of in-filled trenches with pipes in the interception of the railway-induced vibrations. A trench barrier of width $\mathrm{W}$ and depth $\mathrm{D}$ is assumed located at a distance $\mathrm{L}$ measured from the trench centerline to the building left side. The trench width $\mathrm{W}$, depth $\mathrm{D}$ and the distance L are assumed constant parameters for all conditions. The study has been carried out considering different scenarios obtained by varying specified material properties of the in-filled trenches. The values attributed to the material features of pipes and their inside materials are summarized in Table 2, while Soil, In-filled trench and railway foundation properties have been set up according to the Table 1. Two types of loose sand and clay, according to Table 2 have been considered as fulfillment material for in-filled trenches with pipes including steel pipes and concrete pipes. By 


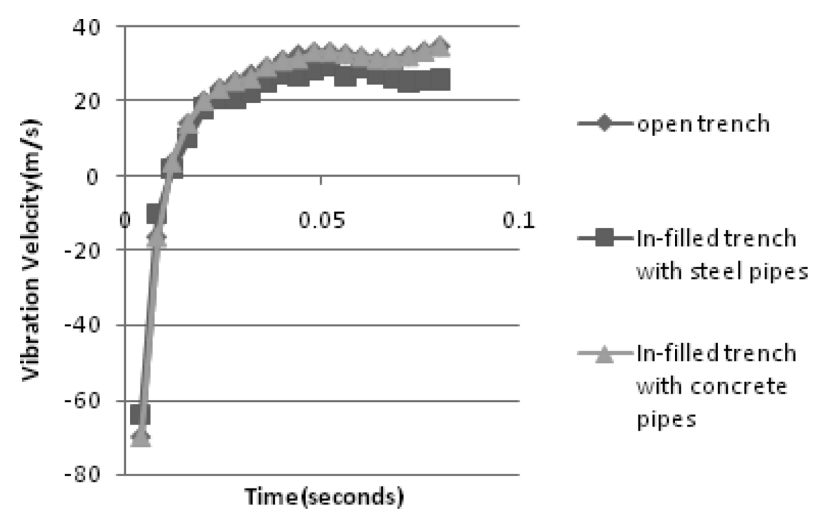

Fig. 15 Vibration reduction efficiency of two different types of in-filled trench with pipes(steel and concrete pipes)

combining all the parameters, many scenarios have been obtained and investigated. The propagation and interception of ground-borne vibrations for each scenario have been modeled by means of the finite elements method. The scheme adopted is shown in Fig. 10. For each scenario, the vibration velocity has been obtained. In particular, this parameter has been calculated in a vibrationsensitive point, nine meters far away the symmetry axis of the railway. Figs. 11 and 12 show schematic detail of Infilled trench with empty pipes problem definition and ABAQUS model of in-filled trench with empty pipes problem respectively. In addition, Figs. 13 and 14 reveal schematic detail of in-filled trench with full pipes problem definition and ABAQUS model of in-filled trench with full pipes problem respectively.

\section{Results and Discussion}

In this part of the paper, the effect of different types of in-filled trenches with pipes including steel and concrete pipes and pipes with loose sand and clay inside will be investigated and compared. Adopting the material properties as in Tables 1 and 2, Fig. 15 below shows vibration reduction efficiency plots for two different types of infilled trench with pipes (steel and concrete pipes). As can be seen in Fig. 15, in comparison to open trench, the infilled trench with concrete pipes has very neglect able efficiency on railway-induced vibration reduction. Instead, infilled trench with steel pipes is much more effective than open trench and in-filled trench with concrete pipes in vibration reduction. In particular, in-filled trench with steel pipes as times increase becomes more effective and can reduce railway-induced vibration. Its reduction efficiency is approximately less than $10 \%$ according to Fig.15. It should be emphasized that during comparison between dif-

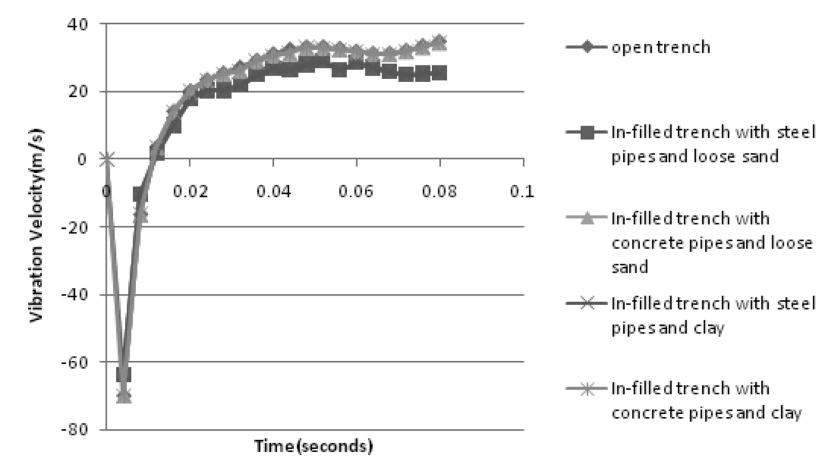

Fig. 16 Vibration reduction efficiency of two different types of in-filled trench with pipes (steel concrete pipes with loose sand and clay)

ferent trenches in this analysis, same length, depths and widths were selected.

Fig. 16 below reveals vibration reduction efficiency plots for two different types of in-filled trench with pipes (steel and concrete pipes) with loose sand and clay inside. As can be seen in Fig. 15, filling pipes with clay and loose sand is not effective anymore in railway-induced vibration reduction.

\section{Conclusions}

Vibration from railways seldom causes structural damage, but is disturbing to occupants as it interferes with speech and communication, interrupts concentration, and disturbs sleep. Modifications to the vibration source, transmission path, and building design can reduce the level of vibration in the building. While ground-borne vibration from railway systems continues to be a significant concern among transit system designers and operators, effective and proven means for control of ground-borne noise and vibration exist in the form of resource reduction methods, propagation path methods and receiver reduction methods. In this Paper, a two-dimensional Finite Element Analysis has been conducted to evaluate the effects of infilled trenches with pipes screening system on decreasing railway-induced vibrations Rayleigh waves by employing ABAQUS computer program and the following conclusions could be distilled:

The existing studies indicate that the effect of in-filled trenches with pipes on the vibration reduction has not been investigated anymore. As a response to this need, in the current study with focusing on in-filled trenches with pipes, two types of in-filled trenches with pipes, (free pipes and full pipes with different materials) have been carried out. For this purpose, phenomenon of vibrations 
due to moving trains was modeled with the numerical finite/infinite elements. According to the results, using infilled trench with pipes does not effective a lot on railwayinduced vibration reduction in comparison to other railway-induced vibration reduction methods; however, infilled trenches with steel pipes are much more effective than in-filled trenches with concrete pipes. Moreover, filling pipes with loose sand and clay does not have any effect on vibration reduction efficiency of these in-filled trenches.

\section{References}

1. Bata M., (1971). "Effects on Buildings of Vibrations Caused by Traffic," Building Science, Vol. 6, pp. 221-246.

2. Younesian D and Sadri M. (2012). "Effects of the Trench Geometry on Vibration Mitigation Level in High-speed Railway Tracks," Journal of Mechanical Science and Technology, Vol. 26, No. 8, pp. 2469-2476.

3. Mosayebi S.A., Zakeri J. A. and Esmaeili M. (2011). Reduction of train induced vibrations on surrounding buildings with using trench, master thesis, Iran University of science and technology, Iran.

4. Esmaeili M., Zakeri J. A., and Mosayebi S.A, (2012). Investigating the effect of the shapes of in-filled concrete trenches on the railway induced vibrations, ninth International congress on civil engineering, Isfahan University of Technology (IUT), Isfahan, Iran, May 8-10.

5. Jabbar-Ali Zakeri, Morteza Esmaeili and Seyed-Ali Mosayebi, (2013). "Numerical Investigation of the Effectiveness of a Step-shaped Trench in Reducing Train-induced Vibrations, Proceedings of the Institution of Mechanical Engineers," Part F: Journal of Rail and Rapid Transit, Vol. 0, No. 0, pp. 1-9.

6. Xia He, Cao Yanmei, Zhang N. (2005). "Experimental Study of Train-induced Vibrations of Environments and Buildings," Sound \& Vibration, Vol. 280, pp. 1017-1029

7. Yang YB and Hung HH. (2008). Wave propagation for train induced vibrations, a finite/infinite element approach. Singapore: World Scientific Publishing.

8. Kawamura S, Ito S, Yoshida T and Minamoto H. (2011). "Isolation Effect of a Dynamic Dashpot and a Trench on Ground Vibration Caused by a Construction Machine," Appl
Acoust, Vol. 72, No. 4, pp. 151-156.

9. Di Mino G, Giunta M and Di Liberto CM. (2009). Assessing the open trenches in screening railway ground-borne vibrations by means of artificial neural network, Adv Acoust Vib: 1-12.

10. XIA He, CAO Yanmei, De Roeck Guido, Degrande Geert, (2007). Environmental problems of vibrations induced by railway traffic, Higher Education Press and Springer-Verlag

11. Kirsty Alison Kuo, (2010). Vibration from Underground Railways: Considering Piled Foundations and Twin Tunnels, a dissertation submitted for the degree of Doctor of Philosophy.

12. L. Andersen and S.R.K. Nielsen, (2005). Reduction of ground vibration by means of barriers or soil improvement along a railway track, Soil Dynamics and Earthquake Engineering.

13. A. Zach and G. Rutishauser, (1989). Measures against structure borne noise and vibrations: experience from projects carried out by Swiss Federal Railways (SBB), Report DT 217, Office for Research and Experiments of the International Union of Railways, Utrecht, Netherlands.

14. R. Wettschureck and U.J. Kurze, (1985). "Insertion Loss of Ballast Mats," Acoustics Vol. 58, pp. 177-182.

15. R. Wettschureck, (1995). Vibration and structure-borne noise insulation by means of cellular polyurethane (PUR) elastomers in railway track applications, Rail Engineering International Edition, 7-14.

16. R. Wettschureck, (1997). Measures to reduce structure-borne noise emissions induced by above ground open railway lines, Rail Engineering International Edition, 12-16.

17. G.P. Wilson, H.J. Saurenman, and J.T. Nelson, (1983). "Control of Ground Borne Noise and Vibration," Journal of Sound and Vibration Vol. 87, pp. 339-350.

18. L. G. Kurzweil. (1979). Ground-born noise and vibration from underground rail systems, Journal of Sound and Vibration, Volume 66, Issue 3, p. 363-370.

19. V. Knall. (1996). "Railway noise and vibration: effects and criteria," Journal of Sound and Vibration, Vol. 193, No. 1, pp. 9-20.

20. Hung, H. H., Yang. Y. B., F.ASCE., and Chang D. W., (2004). "Wave Barriers for Reduction of Train-induced Vibrations in Soils," Journal of Geotechnical and Geo-environmental Engineering, Vol. 130, No. 12, pp. 1283-1291. 